\title{
The Hazard from Plutonium Dispersal by Nuclear-warhead Accidents
}

\author{
Steve Fetter and Frank von Hippel
}

Published in Science and Global Security, Vol. 2, No. 1 (1990), pp. 21-41.

Nuclear weapons are carefully designed to have an extremely low probability of exploding accidentally with an appreciable yield - even if they are involved in a high-speed crash, struck by a bullet or consumed in a fire. ${ }^{1}$ The principal concern when nuclear warheads are involved in such accidents is the possible dispersal of plutonium into the environment. In particular, an explosion could disperse a significant fraction of the plutonium in a warhead as particles of respirable size. ${ }^{2}$

There are two incidents of which we are aware in which the chemical high explosive (HE) in U.S. nuclear warheads exploded and contaminated an area with plutonium: ${ }^{3}$

- In January 1966, over Palomares, Spain, a mid-air collision between a B-52 and its refueling aircraft resulted in four bombs from the B-52 being released. The braking parachutes of two bombs failed completely and they struck the ground at high speed. The HE exploded, and plutonium was widely dispersed. Cleanup and reparation cost $\$ 100$ million.

- In January 1968, near Thule, Greenland, a fire broke out on a B-52. The bomber was abandoned and crashed into the ice at high speed and burned; the HE in the four bombs it carried exploded, spreading plutonium widely over the ice. ${ }^{4}$

Almost immediately after the Thule accident, the U.S. Air Force stopped routinely flying its bombers with nuclear weapons. In addition, most U.S. nuclear

\footnotetext{
${ }^{1}$ U.S. Nuclear weapons are designed so that "in the event of a detonation initiated at any one point in the high explosive system [rather than multiple points, which would occur if the authorization code were properly entered and the environmental sensors registered the design launch-to-target sequence], the probability of a nuclear yield greater than 4 pounds [1.8 kilograms] TNT equivalent shall not exceed one in one million." U.S. Arms Control and Disarmament Agency, Fiscal Year 1979 Arms Control Impact Statements, p. 92.

${ }^{2}$ A survey of experiments involving the burning of plutonium metal in hot fires found that the fraction of plutonium converted into a respirable $\mathrm{PuO}_{2}$ aerosol ranges from less than 0.001 percent to a few percent. Ralph Condit, Plutonium Dispersal in Fires: Summary of What is Known (Livermore, CA: Lawrence Livermore National Laboratory, 1986), p. 10.

${ }^{3}$ Ibid., p. 11.

${ }^{4}$ For a report on measurements of plutonium contamination and of the cleanup, see USAF Nuclear Safety Study 65 (Kirtland AFB, NM: Directorate of Nuclear Safety, 1970), part 2, "Project Crested Ice."
} 
warheads designed during the last decade use "insensitive high explosive" (IHE), which is unlikely to be detonated by even high-speed impacts.

However, many of the older warheads still in the U.S. nuclear arsenal and, for various reasons, a few of the newer ones - most notably the W88 warhead for the Trident II-still contain ordinary HE. Recently, the U.S. weapon laboratories have chosen to raise the safety problems of these warheads as an issue. ${ }^{5}$ The purpose of this article is to offer some perspective on this concern.

Consider a hypothetical worst-case accident in which the HE in several nuclear warheads explodes. Based on experiments and calculations, it has been estimated that 10-100 percent of plutonium contained in the warheads, with a best estimate of 20 percent, could be converted by such explosions into a $\mathrm{PuO}_{2}$ aerosol of respirable size (median aerodynamic diameter in the range of 5 microns or less). ${ }^{6}$ If we assume a missile carrying about 10 warheads, and that each of the warheads contains approximately 3 kilograms of plutonium, then the resulting aerosol would contain on the order of 10 kilograms of $\mathrm{PuO}_{2}{ }^{7}$

\section{HEALTH RISKS FROM PLUTONIUM AEROSOLS}

The principal risk from exposure to a plutonium aerosol is via inhalation: most of the radiation emitted by plutonium is in the form of alpha particles, which have such short range (about 50 microns in tissue) that they cannot even penetrate the skin. External radiation from the passing cloud and from plutonium deposited on the ground can therefore be neglected. ${ }^{8}$ For an aerosol of 1-micron median aerodynamic

\footnotetext{
${ }^{5}$ R. Jeffrey Smith, "Defective Nuclear Shells Raise Safety Concerns," Washington Post, 23 May 1990, A-1. In a letter to Senator Kennedy, dated 9 July 1990, Brent Scowcroft, President Bush's national security advisor, argued that "recent revelations regarding the safety of certain warheads underscores the importance of testing."

${ }^{6}$ Supplementary Documentation for an Environmental Impact Statement Regarding the Pantex Plant (Los Alamos National Laboratory, report LA-9445-PNT-D, 1982); Report on the Safety Criteria for PlutoniumBearing Nuclear Weapons (Washington, DC: U.S. Atomic Energy Agency, report RS/5640/1032, 23 January 1973; declassified with deletions, 9 January 1989), p. 10.

${ }^{7}$ We infer from note 6 that at least some nuclear weapons contain plutonium-238 to power a radioisotope thermoelectric generator (RTG). The amount of plutonium-238 depends on the power requirements for nuclear weapons; 1 gram of plutonium-238 generates about 0.57 watts of heat, which could be converted to no more than 0.06 watts of electric power. Although 14.5 grams of plutonium-238 presents about the same health hazard as 4 kilograms of plutonium-239 (assuming the hazard scales with radioactivity), it could only be used to generate about 1 watt of electrical power. If power requirements are greater than 1 watt, then plutonium-238 should be considered in a hazard analysis. We do not, however, know what the power requirements of nuclear weapons are, and in any case the plutonium-238 in the RTG should be much better protected from dispersal during an accident than the plutonium core. We therefore ignore the contribution of plutonium-238 to health effects in this paper, although we flag the issue here.

${ }^{8}$ The amount of the aerosol inhaled in proportional to its concentration $\mathrm{c}_{0}$ in the air (measured in $\mathrm{mg} / \mathrm{m}^{3}$ ) and the length of exposure $\left(\mathrm{T}_{0}\right)$. The dose due to inhalation will then be $\mathrm{D}_{\mathrm{i}} \mathrm{bT}_{0} \mathrm{c}_{0}$, where $\mathrm{b}$ is the breathing rate (about
} 
diameter, about 15 percent of the inhaled $\mathrm{PuO}_{2}$ would be retained in the deep lung with a retention half-life of about 1.4 years. ${ }^{9}$

Health effects from radiation exposure are often divided into two categories: illnesses and deaths due to high doses, occurring within a year or so after exposure, and cancers due to low doses, occurring during the remainder of the lives of the exposed population, starting a few years after exposure. As shown in the appendix, high-dose effects are unlikely even in a worst-case plutonium-dispersal accidentespecially beyond the boundary of a military base. We therefore focus here on the cancer risk.

The principal hazard from exposure to lower concentrations of $\mathrm{PuO}_{2}$ aerosols is an increased probability of cancer of the lung and of other organs to which the plutonium is transported, particularly the bone. A recent review of the risks associated with low radiation doses from inhaled alpha emitters obtained a (very rough) risk estimate of one cancer death per 1,400 lung-rad and 900 to 12,000 bonerad for inhaled $\mathrm{PuO}_{2}{ }^{10}$

The 30-year dose-conversion factors in the literature for lung and bone-surface doses range respectively from 1,600-3,700 and 3,200-11,000 rads per inhaled milligram of ${ }^{239} \mathrm{PuO}_{2}$ aerosol with a median aerodynamic diameter of 1 micron. ${ }^{11}$

$3.3 \cdot 10^{-4} \mathrm{~m}^{3} / \mathrm{s}$ for an adult male involved in light activity) and $\mathrm{D}_{\mathrm{i}}$ is the dose per milligram of plutonium aerosol inhaled. Below, we will see that $\mathrm{D}_{\mathrm{i}} \approx 3,800$ and 7,600 rads per milligram for the lung and bone-lining cells-the organs in which the cancer risk would be greatest following the inhalation of $\mathrm{PuO}_{2}$. The external whole-body dose from the cloud would be $\mathrm{D}_{\mathrm{c}} \mathrm{c}_{0} \mathrm{~T}_{0}$ and the external dose from plutonium deposited on the ground would be $\mathrm{D}_{\mathrm{g}} \mathrm{c}_{0} \mathrm{~T}_{0} \mathrm{vT}$. $\mathrm{D}_{\mathrm{c}} \approx 1.2 \cdot 10^{-8} \mathrm{rad} \mathrm{m}^{3} \mathrm{mg}^{-1} \mathrm{~s}^{-1}, \mathrm{D}_{\mathrm{g}}=6.6 \cdot 10^{-10} \mathrm{rad} \mathrm{m}^{2} \mathrm{mg}^{-1} \mathrm{~s}^{-1}$ for plutonium-239, $\mathrm{v}$ is the deposition velocity (of order $10^{-2}$ meters per second in the absence of rain), and $\mathrm{T}$ is the duration of exposure to the contaminated ground in seconds. The ratio of cloud to inhalation dose is therefore $\mathrm{D}_{\mathrm{c}} /\left(\mathrm{bD}_{\mathrm{i}}\right) \approx 10^{-8}$, and the ratio of the ground to lung inhalation dose is $\left(\mathrm{D}_{\mathrm{g}} \mathrm{Tv}\right) /\left(\mathrm{bD}_{\mathrm{i}}\right) \approx 4 \cdot 10^{-12} \mathrm{~T}$. Since the lung would account for a significant fraction of all cancers caused by external whole-body gamma radiation, the cloud dose brings with it negligible risk, and it would take about 10,000 years for the integrated ground dose to equal the inhalation dose. The ratios for plutonium-239 are similarly low. See Steve Fetter, Internal Dose Conversion Factors of 19 Target Organs and 9 Irradiation Times and External Dose-rate Conversion Factors for 21 Target Organs for 259 Radionuclides Produced in Potential Fusion Reactor Materials, (Idaho Falls: Idaho National Engineering Laboratory, report EGG-FSP-8036, 1988). ${ }^{9}$ Reactor Safety Study (Washington, DC: U.S. Nuclear Regulatory Commission, report NUREG-75/014, 1975), appendix VI, pp. D-2-D-7.

${ }^{10}$ Health Risks of Radon and Other Internally Deposited Alpha-Emitters: BIER IV (Washington, DC: National Academy Press, 1988), p. 332-334.

${ }^{11}$ According to table 23 of Ionizing Radiation: Sources and Biological Effects (New York: United Nations, 1982), the average dose commitment to the human lung and the bone-lining cells from the inhalation of $\mathrm{PuO}_{2}$ from atmospheric nuclear testing is 1.6 and 4.8 millirads per becquerel, respectively. Since plutonium- 239 has a specific activity of 0.06204 curies per gram, this translates to 3,700 and 11,000 rads per milligram.

Reactor Safety Study (Washington, DC: U.S. Nuclear Regulatory Commission, 1975), table VI D-2, gives a 30 -year dose to the lung and bone of $2.9 \cdot 10^{8}$ and $5.2 \cdot 10^{8}$ rem per curie. Since the study set $\mathrm{Q}=10$ rem per rad for alpha particles, this translates to 1,800 and 3,200 rads per milligram. 
We use the values of 3,200 and 6,500 rads per milligram here. ${ }^{12}$ After correcting for the 6 percent plutonium-240 in weapon-grade plutonium $(\mathrm{WgPu}),{ }^{13}$ the lung and bone dose-conversion factors are 3,800 and 7,600 rads per milligram, respectively. The total (lung plus bone) cancer risk is therefore 3 to 11 cancer deaths per milligram of $\mathrm{WgPu}$ aerosol inhaled.

For comparison, the method of estimating cancer risk advocated by the International Commission on Radiological Protection (ICRP) is to use an "effective dose equivalent" (EDE), which is the weighted average of the dose to certain organs, with the weights determined by the relative probability that a fatal cancer will occur in that organ after a uniform whole-body dose. The EDE for ${ }^{239} \mathrm{PuO}_{2}$ aerosol is 15,000 rem per milligram, or 18,000 rem per milligram for $\mathrm{WgPu}$. Dividing by the ICRP risk factor of 2,000 rem per cancer death ${ }^{14}$ would give 9 cancer deaths per milligram of $\mathrm{WgPu}$ inhaled.

In the appendix on high-dose effects, it is estimated from experimental data on beagle dogs that the risk of death from pulmonary neoplasia (a cancer) would be approximately 100 percent for the inhalation by a human adult of more than 0.08 milligrams of $\mathrm{WgPu}$, if early death did not occur first as a result of some other cause. If this risk were extrapolated linearly to lower exposures, it would correspond to 12 cancer deaths per milligram of $\mathrm{WgPu}$ inhaled.

Thus, three different methods of estimating cancer risk from inhalation of $\mathrm{PuO}_{2}$ give risk factors in the range of 3 to 12 cancer deaths per milligram of $\mathrm{WgPu}$ inhaled.

D.E. Dunning, Jr., G.G. Killough, S.R. Bernard, J.C. Pleasant, and P.J. Walsh, "Estimates of Internal Dose Equivalent to 22 Target Organs for Radionuclides Occurring in Routine Releases from Nuclear Fuel-Cycle Facilities," vol. III, ORNL/NUREG/TM-190/V3 (Oak Ridge: Oak Ridge National Laboratory, 1981), pp. 43-44, give 50-year DCFs for lung and bone surfaces of 580 and 4,160 rem per microcurie. After dividing by the assumed $\mathrm{Q}=20$ rem per rad for alpha particles and multiplying by the ratio of the 30 -year and 50 -year doses given by Fetter, this translates to 1,600 and 9,300 rads per milligram.

${ }^{12}$ Steve Fetter, "Internal Dose Conversion Factors of 19 Target Organs and 9 Irradiation Times and External Doserate Conversion Factors for 21 Target Organs for 259 Radionuclides Produced in Potential Fusion Reactor Materials," (Idaho Falls: Idaho National Engineering Laboratory, 1988), addendum, gives 30-year lung and bone surface doses of $2.9 \cdot 10^{8}$ and $5.2 \cdot 10^{8} \mathrm{rem} / \mathrm{Ci}$, respectively. Since $\mathrm{Q}=20 \mathrm{rem} / \mathrm{rad}$ for $\alpha$-particles in this study, this translates to 3,200 and $6,500 \mathrm{rad} / \mathrm{mg}$ of ${ }^{239} \mathrm{Pu}$.

${ }^{13}$ The specific activity of fresh weapon-grade plutonium is 1.17 times that of pure plutonium-239. After one halflife (14 years) of plutonium-241, the activity would increase by an additional 10 percent because of the alpha decay of americium-241.

${ }^{14}$ International Commission on Radiological Protection, "Limits for Intakes of Radionuclides by Workers," ICRP Publication 30 (Oxford: Pergamon Press, 1990). 
We make the usual assumption that the risk is linear with dose. ${ }^{15}$ As a result, independently of whether a total of 1 milligram of $\mathrm{PuO}_{2}$ is inhaled by 100 people (an average of 0.01 milligrams per person) or by 1,000 people ( 0.001 milligrams per person) there would be an expected 3-12 cancer deaths as a result.

\section{Dispersal of the Aerosol}

For estimating the amount of plutonium aerosol inhaled by the population downwind of a release, one can use a Gaussian plume model (see the appendix) and explore the dependence of its predictions for different assumed meteorological conditions and population distributions. However, in situations like the present one in which the cancer risk is linearly proportional to exposure with no threshold, a much better "feel" for the estimates can be obtained using an extremely simple atmospheric dispersion model, the "wedge" model. ${ }^{16}$ The simplicity of the results obtained with this model stem from the fact that, as noted above, for a cancer risk that is linearly proportional to the exposure, the total number cancers in the population downwind will depend only on the total amount of the carcinogen inhaled by the population, not on the distribution of the doses within the population. The accuracy of the predictions of the wedge model is such applications is generally comparable to that of the Gaussian plume model because most of the cancers will ordinarily be due to very small doses at great distances from the release point, where a Gaussian plume assumes a shape approximated by the wedge model.

In the wedge model, the concentration of a contaminant is assumed to be constant in the crosswind direction over the wedge opening angle $\theta$ (typically ranging from $0.05-0.3$ radians downwind ${ }^{17}$ ) and in the vertical direction throughout the height $\mathrm{H}$ of the mixing layer (typically $300-2,500$ meters $^{18}$ ). Under these conditions, the amount of plutonium inhaled I (in milligrams) by a person a distance $r$ (in meters) downwind is

$$
\mathrm{I}(\mathrm{r})=\frac{\mathrm{Q}(\mathrm{r}) \mathrm{b}}{\theta \mathrm{rHu}}
$$

\footnotetext{
${ }^{15}$ For a discussion of this approximation, see Health Risks of Radon and Other Internally Deposited AlphaEmitters, appendix II.

16 "Report to the American Physical Society by the Study Group on Light-Water Reactor Safety," Reviews of Modern Physics 47 (1975), p. S45.

${ }^{17}$ Reactor Safety Study, table VI A-1.

${ }^{18}$ Ibid., figures VI A-4 and A-5.
} 
where $\mathrm{Q}(\mathrm{r})$ is the amount of plutonium (in milligrams) that remains in the air at distance $r$ downwind, $b$ is the assumed breathing rate $\left(3.3 \cdot 10^{-4} \mathrm{~m}^{3} \mathrm{~s}^{-1}\right.$ for an adult male performing light activity), ${ }^{19}$ and $\mathrm{u}$ is the wind speed (typically between 0.25 and 7 meters per second ${ }^{20}$ ).

In the absence of rain, the total quantity of airborne material declines with $r$ because of deposition as

$$
\mathrm{Q}(\mathrm{r})=\mathrm{Q}_{0} \mathrm{e}^{-\mathrm{r} / \mathrm{L}}
$$

where $\mathrm{Q}_{0}$ is the amount of plutonium released. The average distance an aerosol particle is carried before deposition is

$$
\mathrm{L}=\mathrm{uH} / \mathrm{v}
$$

where $\mathrm{v}$ is the deposition velocity. For most aerosols, the observed deposition velocities range from 0.001 to 0.1 meters per second. ${ }^{21}$ The recommended values for plutonium aerosols from non-nuclear explosions of nuclear warheads is 0.01 meters per second. ${ }^{22}$ We will assume a range of 0.003 to 0.03 meters per second. $L$ in the absence of rain therefore can range from tens to thousands of kilometers.

In the presence of rain, there would be an additional exponential term associated with a characteristic washout time constant $\tau$ ranging from $10^{3}$ seconds (unstable atmospheric conditions) to $10^{4}$ seconds (stable conditions). ${ }^{23}$ The corresponding wet-deposition velocity

$$
\mathrm{v}_{\mathrm{w}}=\mathrm{H} / \tau
$$

is generally much larger than $\mathrm{v}_{\mathrm{d}}$ with a range of 0.05 to 1 meters per second. Under rainy conditions, the deposition velocities would be added $\left(\mathrm{v}=\mathrm{v}_{\mathrm{d}}+\mathrm{v}_{\mathrm{w}}\right)$.

According to the wedge model, the amount of $\mathrm{PuO} 2$ inhaled by the total population downwind would be

\footnotetext{
${ }^{19}$ Health Risks of Radon and Other Internally Deposited Alpha-Emitters, p. 147. The ratio of breathing rate to lung mass does not vary by more than a factor of two with age (Reactor Safety Study, tables IV D-4 and D-5).

${ }^{20}$ Reactor Safety Study, table VI 5-2.

* It should be noted that, in principle, it would be possible to reduce considerably the amount of plutonium inhaled if the population stayed inside with windows and air intakes closed during the passage of the aerosol cloud and opened up and aired out the buildings immediately after it had passed. See, for example, Bernard Cohen, Health Physics, Vol. 32 (1977), pp. 359-379.

${ }^{21}$ Reactor Safety Study, table VI B-1.

${ }^{22}$ G.A. Schmel, "Particle and Dry Gas Deposition: A Review," Atmospheric Environment, Vol. 14 (1980).

${ }^{23}$ Reactor Safety Study, appendix VI, p. E-13.
} 


$$
I_{p}=\int_{0}^{\infty} I(r) \theta r \rho(r) d r
$$

where $\rho(r)$ is the population density at distance $r$ downwind averaged over the width of the wedge.

If we assume that the population density is constant, equal to $\rho_{0}$, then we find that the total amount of plutonium inhaled is

$$
\mathrm{I}_{\mathrm{p}}=\frac{\mathrm{Q}_{0} \mathrm{~b} \rho_{0}}{\mathrm{v}}
$$

The average population density of the 48 contiguous U.S. states is about 30 per square kilometers; in the most densely populated states of the northeast it ranges around 300 per square kilometer, and 3,000 per square kilometer is a mid-range density for urban areas. For a risk factor of 3-12 cancer deaths per milligram of $\mathrm{WgPu}$ inhaled, table 1 shows our resulting estimates of the number of deaths for various combinations of population density and deposition velocity.

It will be noted that in table 1 the entries associated with very low deposition velocity are not filled in for the highest population density. The reasons are that, for $\mathrm{v}=0.003$ or 0.01 meters per second, $\mathrm{L}$ would most likely be hundreds of kilometers - much larger than any urban area.

We have checked the predictions of the wedge model against the corresponding predictions of the Gaussian plume model and obtained quite close agreement, independent of weather conditions.

Table 1. The number of cancer fatalities caused by inhalation during the passage of a plume initially containing 10 kilograms of $\mathrm{PuO}_{2}$ aerosol for various deposition velocities and average population densities, for a risk factor of 3-12 cancers deaths per milligram of $\mathrm{WgPu}$ inhaled.

Deposition velocity Population density $\rho_{0}\left(\mathrm{~km}^{-2}\right)$

\begin{tabular}{lccc} 
(meters per second) & 30 & 300 & 3,000 \\
\hline 0.003 & $100-400$ & $1,000-4,000$ & - \\
0.01 & $30-120$ & $300-1,200$ & - \\
0.03 & $10-40$ & $100-400$ & $1,000-4,000$ \\
$0.1 \quad$ rain & $3-12$ & $30-120$ & $300-1,200$ \\
$1 . \quad$ rain & $0-1$ & $3-12$ & $30-120$ \\
\hline
\end{tabular}


Although the largest entry in table 1 -four thousand cancer deaths-is high, the increase in the cancer risk for an individual in the exposed population would be small - typically on the order of one tenth of a percent. For example, for average conditions $(\mathrm{H}=1,000$ meters, $\theta=0.2$ radians, $\mathrm{u}=2$ meters per second, and $\mathrm{v}=$ 0.01 meters per second) the additional risk of cancer death would be $0.2-0.9$ percent at a distance of 10 kilometers and 0.02-0.06 percent at a distance of 100 kilometers from the release. The small individual risk reflects the fact that the population risk would typically be spread among a very large population. For comparison, the individual cancer death risk in the U.S. is at present about 20 percent. There may well already be many such large-scale cancer "events" occurring in the U.S. due to the widespread release to the environment of carcinogenic chemicals that remain undetected against this large background. ${ }^{* 24}$

As an illustrative example, we have estimated the consequences if a hypothetical 10-kilogram release of $\mathrm{WgPu}$ aerosol should occur at Bangor Naval Base in Washington state, one of the two bases for U.S. Trident submarines, with the wind blowing towards Seattle. As Bangor is located just 30 kilometers from downtown Seattle, this may represent a near worst case for such an accident. Table 2 gives the radial population density in the direction of Seattle and beyond as a function of distance from Bangor and table 3 gives the wedge-model estimates for the cancer deaths that would result from the release if the wind were blowing in this direction for different combinations of deposition velocity, wind speed and mixing layer height. The average wind speed in Seattle is 4 meters per second, so the average value of $\mathrm{Hu}$ is about $4,000 \mathrm{~m}^{2} \mathrm{~s}^{-1}$, with a range from about 1,000 to 10,000 $\mathrm{m}^{2} \mathrm{~s}^{-1}$. The estimated number of cancer deaths under dry conditions ranges from 20

\footnotetext{
* We note in this connection that approximately 3,000 kilograms of $\mathrm{PuO}_{2}$ was dispersed into the global atmosphere by atmospheric testing during the later 1950s and early 1960s, about 80 percent of it in the northern hemisphere. The resulting average inhalation by humans in the northern hemisphere was 0.13 nanograms. Using the above total cancer risk coefficients, this translates into an incremental cancer risk of 0.4-1.6 cancers per million persons in the northern hemisphere. Assuming that an average population of 3 billion in the northern hemisphere was exposed to the plutonium fallout (corresponding to an average population density of about 10 per square kilometer), about 1,000 to 5,000 people have died or will die from cancer due to plutonium inhalation, or roughly one person per kilogram of plutonium released.

${ }^{24}$ Four thousand cancer deaths in the lifetime of the U.S. population of 250 million corresponds to an average individual risk of about $10^{-5}$. This is in the range where the U.S. Environmental Protection Agency (EPA) tends to set the limits of acceptable risks for the carcinogens that it regulates. [See for example Eliot Marshall, "WPA's High-Risk Carcinogen Policy," Science, Vol. 218 (1982), p. 975.]
} 
to 2,000 . These estimates agree well with the prediction obtained using a formula recommended by the Defense Nuclear Agency."

Table 2. The radial population density in the direction of Seattle from Bangor Naval Base.

\begin{tabular}{lcc} 
Zone & $\begin{array}{c}\text { Distance from } \\
\text { Bangor }(\mathrm{km})\end{array}$ & $\begin{array}{c}\rho(\mathrm{r}) \\
\left(\mathrm{km}^{-2}\right)\end{array}$ \\
\hline Kitsap County & $0-18$ & 130 \\
Puget Sound & $18-28$ & 0 \\
Seattle & $28-38$ & 2300 \\
Lake Washington & $38-41$ & 0 \\
Bellevue & $41-50$ & 1200 \\
East suburbs & $50-70$ & $1200 \mathrm{e}^{-0.24(\mathrm{r}-50)}$ \\
Mountains & $70-\infty$ & 10 \\
\hline
\end{tabular}

Table 3. Cancer deaths predicted by the wedge model for a 10-kilogram release of $\mathrm{WgPu}$ at Bangor Naval Base with the wind blowing towards Seattle.

\begin{tabular}{cccc} 
Deposition & \multicolumn{3}{c}{$\begin{array}{c}\text { Mixing height } \cdot \text { wind speed, Hu } \\
\left(\mathrm{m}^{2} \mathrm{~s}^{-1}\right)\end{array}$} \\
\cline { 2 - 4 } \begin{tabular}{c} 
vecity $\mathrm{v} / \mathrm{s})$ \\
\cline { 2 - 3 }
\end{tabular} & 1,000 & 3,000 & 10,000 \\
0.003 & $400-1700$ & $180-700$ & $80-300$ \\
0.01 & $300-1200$ & $150-600$ & $50-200$ \\
0.03 & $150-600$ & $100-400$ & $40-170$ \\
0.1 rain & $20-90$ & $45-180$ & $30-120$ \\
$1 . \quad$ rain & $1-5$ & $1-5$ & $2-9$ \\
\hline
\end{tabular}

\section{LAND CONTAMINATION}

After the plume passed, it would leave a swath of land contaminated with $\mathrm{PuO}_{2}$. The main hazard associated with this contamination would be that the plutonium might

\footnotetext{
${ }^{*}$ Using a cookbook-style manual written for military commanders to assess the effects of destroying nuclear weapon stockpiles during a war, we have calculated that, over the entire range of meteorological conditions, the number of expected cancer deaths in Seattle alone would be 30-1,000, which compares with then 10-900 cancer deaths given for Seattle by the wedge model. [Field Command, Defense Nuclear Agency, Estimation of the Hazard from Plutonium Dispersal (Kirtland AFB, 1977).]
} 
be resuspended and inhaled. The concentration of the plutonium contamination $\sigma$ $\left(\mathrm{mg} \mathrm{m}^{-2}\right)$ at a particular point is simply related to the amount I that a person located at that point would have inhaled during the passage of the plume

$$
\sigma=\mathrm{vI} / \mathrm{b}
$$

where, once again, $\mathrm{v}$ is the deposition velocity (meters per second) and $\mathrm{b}$ is the breathing rate $\left(\mathrm{m}^{3} \mathrm{~s}^{-1}\right)$.

The ratio of the concentration of resuspended aerosol to $\sigma$ can be characterized by a "resuspension coefficient" $\mathrm{K}$. It is therefore easy to make a comparison between the amount of resuspended plutonium inhaled $\mathrm{I}_{\mathrm{r}}$, and $\mathrm{I}$ if one knows the resuspension coefficient $\mathrm{K}\left(\mathrm{m}^{-1}\right)$ as a function of time:

$$
\frac{I_{r}(t)}{I}=v \int_{0}^{t} K\left(t^{\prime}\right) d t^{\prime}
$$

The resuspension coefficient can be expected to decline with time as the plutonium aerosol sinks into the soil and becomes attached to larger particles. Based on a review of the small amount of available data, a 1974 Atomic Energy Commission study suggested for populated areas an initial value $\mathrm{K}_{0}=10^{-5} \mathrm{~m}^{-1}$ declining to a long-term value of $\mathrm{K}_{\infty}=10^{-9} \mathrm{~m}^{-1}$, and interpolated according to the formula

$$
\mathrm{K}(\mathrm{t})=\mathrm{K}_{0} \mathrm{e}^{-5 \mathrm{t}}+\mathrm{K}_{\infty}
$$

where $\mathrm{t}$ is measured in years. ${ }^{25}$ Using this function, we find

$$
\frac{\mathrm{I}_{\mathrm{r}}(\mathrm{t})}{\mathrm{I}}=\mathrm{v}\left[0.2 \mathrm{~K}_{0}\left(1-\mathrm{e}^{-5 \mathrm{t}}\right)+\mathrm{K}_{\infty} \mathrm{t}\right]
$$

Table 4 shows values of $\mathrm{I}_{\mathrm{r}}(\mathrm{t}) / \mathrm{I}$ calculated for various deposition velocities at 1 month and 1 years (after 1 year the resuspension dose rate will be negligible). Note that resuspension can only be neglected for low to moderate deposition velocities ( $\leq$ 0.01 meters per second) and short exposure times (less than a month).

\footnotetext{
${ }^{25}$ U.S. Atomic Energy Agency Proposed Final Environmental Impact Statement Liquid Metal Fast Breeder Reactor Program (WASH-1535, 1974), appendix II-G.
} 
Table 4. The ratio of the integrated inhaled dose from resuspension to that from plume passage, for several values of the deposition velocity at 1 month and after 1 year.

\begin{tabular}{lcc} 
Deposition & & \\
Velocity & \multicolumn{2}{c}{ Exposure Time, $\tau$} \\
\cline { 2 - 3 } $\mathrm{v}(\mathrm{m} / \mathrm{s})$ & 1 month & 1 year \\
\hline 0.003 & 0.064 & 0.19 \\
0.01 & 0.21 & 0.63 \\
0.03 & 0.64 & 1.9 \\
0.1 rain & 2.1 & 6.3 \\
1.0 rain & 21 & 63 \\
\hline
\end{tabular}

Evacuation and/or decontamination, as was done at Palomares, could reduce the hazard to that part of the population in the most heavily contaminated area. In most cases, however, virtually all of the population dose would come from a very large area (on the order of 1,000 square kilometers for $v=0.01$ ) of lightly contaminated land that might well be prohibitively expensive to either evacuate or decontaminate. The factors $\left[1+\mathrm{I}_{\mathrm{r}}(\infty) / \mathrm{I}\right]$ should therefore probably be used to multiply the cancer death estimates in table 1 except for the largest values of $\mathrm{v}(\geq$ 0.1 meters per second) and in urban areas where the contaminated areas would probably be decontaminated. Table 5 gives the number of cancer deaths from inhalation during and after the plume passage under these assumptions.

Table 5. The number of cancer fatalities caused by inhalation during the passage of a plume initially containing 10 kilograms of $\mathrm{PuO}_{2}$ aerosol for various deposition velocities and average population densities, for a risk factor of 3-12 cancers deaths per milligram of $\mathrm{WgPu}$ inhaled.

\begin{tabular}{lccc} 
Deposition velocity & \multicolumn{3}{c}{ Population density $\rho_{0}\left(\mathrm{~km}^{-2}\right)$} \\
\cline { 2 - 4 } (meters per second) & 30 & 300 & 3,000 \\
\hline 0.003 & $120-500$ & $1,200-5,000$ & - \\
0.01 & $50-200$ & $500-2,000$ & - \\
0.03 & $30-120$ & $300-1,200$ & $1,600-7,000$ \\
0.1 rain & $10-40$ & $100-400$ & $1,000-4,000$ \\
$1 . \quad$ rain & $7-30$ & $70-300$ & $700-3,000$ \\
\hline
\end{tabular}




\section{CONCLUSION}

An accident involving the dispersal of kilogram-quantities of plutonium in aerosol form might, in a worst case (for example, an accident at Bangor Naval Base with the wind blowing toward Seattle with low wind speed and deposition velocity), cause a few thousand cancer deaths during the subsequent decades with a probably undetectable increase in the resulting regional cancer rate. Even under worst-case conditions, no early deaths due to high doses would be expected-certainly not off the base. However, judging from the Three Mile Island and Palomares experiences, the psychological trauma and the costs of reparations and decontaminating the most heavily contaminated areas might be enormous.

To get additional perspective on this risk, let us assume that the probability of a near worst-case accident occurring is 0.1 percent per year. ${ }^{26}$ The expected number of deaths would then be on the order of one per year since, under average conditions, on the order of 1,000 cancer deaths would result from a worst-case accident.

This risk could be reduced, but not completely eliminated, by redesigning and rebuilding warheads with IHE — at a cost. A new warhead costs on the order of $\$ 1$ million and lasts 20-30 years. If old warheads containing sensitive HE were retired an average of 10 years early in order to replace them with warheads containing IHE, the extra cost would be at least $\$ 300,000$ per warhead. If this were done for the approximately 3,000 warheads that are to be deployed on U.S. submarines after the reductions mandated by START, the cost would be on the order of $\$ 1$ billion, or $\$ 100$ million per year of reduced risk. Given that the expected value of the number of lives saved by such an expenditure is on the order of one life or less per year, the resulting cost per life saved would be 250-3,000 times that for other investments in life-saving that the U.S. is currently making. ${ }^{27}$

We therefore conclude that reducing the hazard of plutonium dispersal by converting warheads to IHE need not be dealt with by a "crash" program. However,

\footnotetext{
${ }^{26}$ The two large plutonium releases from U.S. nuclear weapons that occurred in the first 50 years of the nuclear age were in areas of low population density, and the practice that resulted in these releases-routine flights by nuclear-armed bombers-has been discontinued.

${ }^{27}$ Bernard Cohen, "Reducing the Hazards of Nuclear Power: Insanity in Action," Physics and Society, Vol. 16 (1987), p. 2, quotes cost estimates in the range of $\$ 20,000-140,000$ per life saved for various types of cancer screening, $\$ 400,000$ for kidney dialysis, and $\$ 30,000-300,000$ per life saved for various highway improvement programs undertaken by the U.S. Department of Transportation in the early 1980s.
} 
for warheads that a government expects to replace upon their retirement, it would be desirable to have available replacement designs containing IHE. If such designs are not available already, their development should be given priority in any further testing before the achievement of a comprehensive test ban.

Another hazard that has been hinted at in the recent press stories on warhead safety is that, under certain conditions, detonation of the chemical explosive in a warhead might result in a nuclear yield greater than 4 pounds of TNT equivalent. Specifically, there is apparently concern that this might occur in case of nearsimultaneous explosions of the HE in the W88 warheads of a Trident-II missile, which are closely clustered around the third-stage rocket motor. ${ }^{28}$ It is difficult for us to provide any perspective on this concern in the absence of public estimates of the size of the nuclear yield that might result in such an event.

\section{Appendix \\ THE RISK OF HIGH-DOSE EFFECTS}

\section{Health Effects at High Doses}

Because it is relatively insoluble, a substantial fraction of inhaled $\mathrm{PuO}_{2}$ will remain in the lungs for a long time. Early effects are therefore dominated by damage to lung tissue.

Experiments with beagle dogs indicate that, if a relatively large amount of aerosol were inhaled, the lung damage from the resulting alpha irradiation would cause death from acute respiratory failure within a week. This would occur for an initial alveolar deposition of about 60 micrograms of ${ }^{239} \mathrm{PuO}_{2}$ per gram of bloodless lung, ${ }^{29}$ which corresponds to a total inhalation of about $100 \mathrm{mg}$ of weapon-grade plutonium $(\mathrm{WgPu})$ by an adult human. ${ }^{30}$

\footnotetext{
${ }^{28}$ R. Jeffrey Smith, "Defective Nuclear Shells Raise Safety Concerns," Washington Post, 23 May 1990, p. A-1.

${ }^{29}$ W.J. Bair, J.E. Ballou, J.F. Park, and C.L. Sanders, "Plutonium in Soft Tissues with Emphasis on the Respiratory Tract," in H.C. Hodge, J.N. Stannard, and J.B. Hursh, eds., The Handbook of Experimental

Pharmacology, Vol. 36: Uranium-Plutonium-Transplutonic Elements (New York: Springer-Verlag, 1973), p. 548.

30 The specific alpha activity of fresh weapon-grade plutonium (6 percent plutonium-240) is 72.5 microcuries per milligram-1.17 times that of plutonium-239. The bloodless lung of man weighs about 500 grams. The fraction of inhaled material initially deposited in the alveoli ranges from 5 to 50 percent for aerosols with a mass median aerodynamic diameter (MMAD) of 10 to 0.2 microns; for an MMAD of 1 micron, the fraction is 25 percent. Thus, 100 milligrams of $\mathrm{WgPu}$ inhaled is equivalent to an alveolar deposition of 0.06 milligrams of plutonium-239 per gram of bloodless lung. In a human being, about 60 percent of this deposition would remain in the lung with a retention half-life of 1.4 years.
} 
The same set of experiments with dogs indicates that, at lower doses, death occurs later because of respiratory insufficiency resulting from extensive fibrosis. The deposition of 2 micrograms of ${ }^{239} \mathrm{PuO}_{2}$ per gram of bloodless lung (corresponding to the inhalation of about 3 milligrams of $\mathrm{WgPu}$ by an adult human) will result in death within several months. ${ }^{31}$ At still lower doses, fibrosis develops more slowly. A least-squares fit to the relationship between Y, the initial alveolar deposition in micrograms of plutonium-239 per gram of lung and the average length of time in days before the deaths of dogs given that dose is ${ }^{32}$

$$
\mathrm{Y}=560 \mathrm{t}^{-1.028}
$$

At the maximum lifetime of a beagle (15 years) this relationship gives an alveolar deposition of 0.09 micrograms of ${ }^{239} \mathrm{PuO}_{2}$ per gram of bloodless lung. (This also happens to be the lowest dose at which a dog died of fibrosis in the experiment.)

Pulmonary neoplasia (a cancer) began to occur in dogs that survived 3 to 5 years after exposure in these experiments and was the cause of death in exposed dogs that survived more than 5 years. The least-squares fit to the dose-longevity curves for dogs dying of neoplasia is ${ }^{33}$

$$
\mathrm{Y}=11,000 \mathrm{t}^{-1.416}
$$

This curve intersects the maximum beagle lifetime at $\mathrm{Y}=0.04$ micrograms per gram, which corresponds to a inhalation of about 0.08 milligrams of $\mathrm{WgPu}$ by an adult human.

\section{Dispersal of the Aerosol at Short Distances}

The inhalation high doses that are the subject of this appendix would occur, if at all, close to the release where the approximations made to obtain the wedge model would not hold. For the purposes of estimating high-dose health effects from an accident we have used a Gaussian plume model to estimate the dispersal of plutonium at short distances. In this model, the time-integrated ground-level concentration of plutonium $\left(\mathrm{mg} \mathrm{s} \mathrm{m}^{-3}\right)$ downwind from the release is given by

\footnotetext{
31 The dose-mortality curve in Bair, et al., "Plutonium in Soft Tissues," p. 548, gives an initial alveolar deposition of 2 micrograms per gram for a survival time of 6 months, which corresponds to an adult inhaling 3 milligrams of $\mathrm{WgPu}$.

32 Ibid., p. 548.

${ }^{33}$ Ibid.
} 


$$
\chi(x, y)=\frac{Q(x)}{\pi \sigma_{y} \sigma_{z} u} \exp \left[-\frac{y^{2}}{2 \sigma_{y}^{2}}-\frac{z^{2}}{2 \sigma_{z}^{2}}\right]
$$

where $\mathrm{x}$ is the downwind distance and $\mathrm{y}$ is the crosswind distance $(\mathrm{m}), \mathrm{Q}(\mathrm{x})$ is the mass (milligrams) of plutonium aerosol remaining in the cloud when it arrives at $\mathrm{x}$, $\sigma_{\mathrm{y}}$ and $\sigma_{\mathrm{z}}$ are the horizontal and vertical standard deviations of the cloud concentration at point $\mathrm{x}, \mathrm{u}$ is the mean wind speed $(\mathrm{m} / \mathrm{s})$, and $\mathrm{h}$ is the centerline height of the cloud. Formulae for $\sigma_{\mathrm{y}}$ and $\sigma_{\mathrm{z}}$ for a point source are given in the Reactor Safety Study for atmospheric conditions ranging from very unstable (class "A") to very stable (class "F"), ${ }^{34}$ we have modified these formulas so that they give the initial standard deviations of the explosion-formed cloud, $\sigma_{\mathrm{y}}{ }^{0}$ and $\sigma_{\mathrm{z}}{ }^{0}$, at $\mathrm{x}=0$, and so that they are appropriate for an instantaneous (rather than a continuous) release. Since the mixed layer of atmosphere normally has a finite height $\mathrm{H}$ (typically 300 to 2,500 meters), we have also modified equation 13 to prevent plutonium from diffusing above the mixed layer and to account for reflections from the top of the mixed layer and the ground.

The amount of plutonium remaining in the cloud at distance $x$ is given by

$$
\mathrm{Q}(\mathrm{x})=\mathrm{Q}_{0} \exp \left[-\sqrt{\frac{2}{\pi}} \frac{\mathrm{v}}{\mathrm{u}} \int_{0}^{\mathrm{x}} \frac{\mathrm{dr}}{\sigma_{\mathrm{z}}} \mathrm{e}^{\frac{-\mathrm{h}^{2}}{2 \sigma_{\mathrm{z}}^{2}}}\right]
$$

where $\mathrm{Q}_{0}$ is the initial amount of plutonium in the cloud (mg) and $\mathrm{v}$ is the deposition velocity of the aerosol $(\mathrm{m} / \mathrm{s})$. As mentioned above, a worst-case accident might involve the detonation of the HE in several ballistic-missile warheads (and perhaps the missile propellants as well), releasing as much as $10 \mathrm{~kg}\left(10^{7} \mathrm{mg}\right)$ of $\mathrm{WgPu}$ as respirable particles. As noted above, depending on the size and composition of an aerosol, $\mathrm{v}$ can range from 0.001 to $0.1 \mathrm{~m} / \mathrm{s}$; a typical value for plutonium is 0.01 $\mathrm{m} / \mathrm{s}$.

The initial height (h) and size $\left(\sigma_{\mathrm{y}}^{0}\right.$ and $\left.\sigma_{\mathrm{z}}^{0}\right)$ of the cloud depends on the amount of explosive energy released. (Cold, ground-level releases from smoldering chunks of plutonium are not considered credible. ${ }^{35}$ ) Since reentry vehicles typically weigh 100 to $200 \mathrm{~kg}$, warheads probably contain 20 to $50 \mathrm{~kg}$ of HE. Since normal HE is nearly twice as energetic as TNT, an accident could result in an explosion

\footnotetext{
34 The Reactor Safety Study, table VI A-1.

${ }^{35}$ Report on the Safety Criteria for Plutonium-Bearing Nuclear Weapons, Appendix, p. 28.
} 
equivalent to between 40 and more than $400 \mathrm{~kg}$ of TNT, depending to the number of warheads involved. The detonation of the propellants in the third stage of a missile would be equivalent to an additional 4 to 8 tons of TNT. ${ }^{36}$ Estimates of the initial cloud heights and radii for low, medium, and high energy releases are given in table $6 .{ }^{37}$ As else being equal, smaller explosions are more dangerous because the plutonium-bearing cloud remains closer to the ground.

Table 6. Cloud-top height and mean radius in meters for low, medium, and high energy releases from an accident involving the detonation of the $\mathrm{HE}$ in one or more nuclear weapons and possibly the third stage of a ballistic missile as well.

\begin{tabular}{lccc} 
Estimate & $\begin{array}{c}\text { Yield } \\
(\mathrm{kg} \mathrm{TNT})\end{array}$ & $\begin{array}{c}\text { Cloud-top } \\
\text { height }(\mathrm{m})\end{array}$ & $\begin{array}{c}\text { Mean } \\
\text { radius }(\mathrm{m})\end{array}$ \\
\hline Low & 40 & 230 & 19 \\
Medium & 400 & 410 & 44 \\
High & 4,000 & 740 & 110 \\
\hline
\end{tabular}

Experiments have shown that approximately 5 percent of the radioactivity in the cloud is initially found between the ground an $\mathrm{T} / 4$, where $\mathrm{T}$ is the cloud-top height; 30 percent between T/4 and T/2; 40 percent between $\mathrm{T} / 2$ and 3T/4; and 25 percent between $3 \mathrm{~T} / 4$ and $\mathrm{T}$. We have modeled this situation by using four cloud sources containing the above fractions of plutonium with centerline heights of $\mathrm{T} / 8$, $3 \mathrm{~T} / 8,5 \mathrm{~T} / 8$, and $7 \mathrm{~T} / 8 ; \sigma_{\mathrm{y}}{ }^{0}$ of $\mathrm{R} / 4, \mathrm{R} / 3, \mathrm{R} / 2$, and $\mathrm{R} / 2$, where $\mathrm{R}$ is the initial cloud radius; and $\sigma_{\mathrm{z}}{ }^{0}$ equal to $\mathrm{T} / 8 .{ }^{38}$

\footnotetext{
${ }^{36}$ Assume a third stage carrying ten warheads weighing 100 to 200 kilograms each gives them a velocity increment of 2.5 kilometers per second. Also assume that the post-boost vehicle (including propellants) weighs as much as the warheads, and that the total stage mass is 1.1 times the propellant mass. Then, using the rocket formula, the propellant mass in the third stage would be equal to $(\mathrm{e}-1) \cdot 2 \cdot 10 /(1.1-0.1 \mathrm{e})=40$ times the mass of a single warhead, or 4 to 8 tonnes in all.

${ }^{37}$ H.W. Church, Cloud Rise from High Explosive Detonations (Albuquerque, NM: Sandia National Laboratory, report TID-4000, UC/41, 1969), gives the following formulas for the cloud-top height T and the cloud radius R: T $=76 \mathrm{~W}^{0.25}$, and $\mathrm{R}=3.5 \mathrm{~W}^{0.375}$, where $\mathrm{T}$ and $\mathrm{R}$ are in meters and $\mathrm{W}$ is in pounds of TNT equivalent.

${ }^{38}$ Supplementary Documentation for Environmental Impact Statement Regarding the Pantex Plant: Dispersion Analysis for Postulated Accidents, LA-9445-PNTX-D (Los Alamos, NM: Los Alamos National Laboratory, 1982).
} 
The amount of plutonium that would be inhaled by an individual (in milligrams) standing on open ground is given by

$$
\mathrm{I}(\mathrm{x}, \mathrm{y})=\chi(\mathrm{x}, \mathrm{y}) \mathrm{b}
$$

where $b$ is the breathing rate $\left(\mathrm{m}^{3} / \mathrm{s}\right)$. As noted above, for an adult male performing light activity, $b=20$ liters per minute $=3.3 \cdot 10^{-4} \mathrm{~m}^{3} \mathrm{~s}^{-1}$.

Table 7 gives the results of the Gaussian plume model for a 10-kilogram release of $\mathrm{WgPu}$ under conditions that result in the highest doses to individuals $(\mathrm{u}=$ $1 \mathrm{~m} / \mathrm{s}, \mathrm{H}=300 \mathrm{~m}$ ) for unstable, stable, and neutral conditions. ${ }^{39}$ A maximum dose approaching 0.08 milligrams - the lowest dose likely to cause threshold effectsoccurs only at close ranges ( $<500$ meters) and low wind speeds $(\leq 1$ meter per second). Therefore doses exceeding 0.08 milligrams are highly unlikely to occur anywhere near civilian populations.

Table 7. The amount of plutonium inhaled by an individual (milligrams) during the plume passage at several points downwind on the plume centerline for unstable, neutral, and stable conditions, under worst-case assumptions about wind speed $(\mathrm{u}=$ 1 meter per second), plume height (40-kilogram equivalent TNT explosive energy release) and thickness of the mixed layer $(\mathrm{H}=300$ meters $)$.

\begin{tabular}{cccc}
$\begin{array}{c}\text { Distance down- } \\
\text { wind }(\mathrm{km})\end{array}$ & unstable & $\begin{array}{c}\text { Dose (milligrams) } \\
\text { neutral }\end{array}$ & stable \\
\hline 0.1 & 0.08 & 0.07 & 0.08 \\
0.2 & 0.1 & 0.06 & 0.06 \\
0.5 & 0.07 & 0.04 & 0.05 \\
1 & 0.03 & 0.03 & 0.03 \\
2 & 0.02 & 0.02 & 0.02 \\
5 & 0.003 & 0.014 & 0.011 \\
10 & 0.002 & 0.011 & 0.006 \\
\hline
\end{tabular}

39 The dose at a given point is approximately inversely proportional to $u$ and, at distances of less than 10 kilometers, is relatively insensitive to factor-of-ten increases in $\mathrm{v}$ and $\mathrm{H}$. 


\section{Summary}

If the area around the release is evacuated after the plume passes to avoid chronic exposure to deposited plutonium, there will almost certainly be no acute health effects from a worst-case accident, even close to the site and under worst-case weather conditions. This is especially true of civilian populations, which are usually no closer than a few kilometers from locations where missiles or nuclear weapons are loaded or stored. Even if the surrounding population was not evacuated and the land was not decontaminated for long periods of time (conditions that are highly unlikely), the maximum off-site dose would exceed 0.08 milligrams only under a very limited set of weather conditions combined with a very low cloud height. Therefore, for all practical purposes, threshold health effects from such accidents can be ignored. 